International Journal of Child, Youth and Family Studies (2013) 3: 357-370

\title{
A BRIDGE TO ALIEN-NATION: CONNECTING THROUGH HUMANITY, DIVERSITY, AND RELATIONSHIPS
}

\section{Felice Yuen and Gabriell Context(e}

\begin{abstract}
This paper is a reflexive process that considers the practices of mainstream service providers that aim to support marginalized youth but unintentionally result in further oppression. To engage in this deconstructive exercise, we use a poem that was written in response to an activity done at a youth engagement workshop held in Montreal in June 2012. Coupled with existing literature and further reflections of a young person's experiences with social service providers, we offer recommendations for meaningful and empowering ways to connect with alienated youth. These recommendations emphasize acknowledging the diversity of experiences, developing authentic relationships, and embracing the humanity that unites us all.
\end{abstract}

Keywords: diversity, humanity, poetry, marginalized youth, reflexivity, youth-adult relationships, youth empowerment

Felice Yuen, Ph.D. (the corresponding author) is an Associate Professor in the Department of Applied Human Sciences at Concordia University, 7141 Sherbrooke Street West, Montreal, Quebec, H4B 1R6. E-mail: felice.yuen@concordia.ca

Gabriell Context(e is a runaway, survivor, mental health advocate, and trans*-youth-adult-indifficulty, Montreal, Quebec, sharing on twitter.com/frets, facebook.com/prosody and tilTrue.com. E-mail: prosody@facebook.com 
The purpose of this article is to consider mainstream practices that aim to include, empower, and support marginalized youth, but unintentionally result in further oppression. As argued by Fox and Lashua (2010), "inclusion processes typically and predominantly focus on how 'to help' people on the margins without questioning the value, 'goodness,' and change requirements of the dominant status quo" (p. 230). Through a reflexive process, we pause to consider the perspectives of youth who locate themselves on the fringes of society and propose recommendations for potential change in adult-youth interactions ${ }^{1}$. Gabriell offers a first-hand perspective as a trans ${ }^{* 2}$ youth who has felt marginalized from self-empowerment. Felice offers the perspective of a researcher whose interactions with Gabriell encouraged her to question and ultimately engage in the deconstruction of dominant paradigms and knowledge.

Marginalization and alienation are used interchangeably throughout the paper. It was Gabriell's idea to use the word alien in the title of this article. The term alien reflects the identity $\mathrm{ze}^{3}$ was given through interactions with adult role models and social service providers. In other words, youth on the margins are aliens and the experience of marginalization is alienating. Upon further reflection, Gabriell writes:

Systems do not easily connect with us. We are alien to them. Aliens are treated like unknowns. Aliens experience a great loss of understanding. Aliens are strangers. Young people need to feel human, but often are left feeling removed again and again.... I do not like that my status is nearly so officially alien. It does not feel necessary.

The alien identity created, in part, through interactions with others reinforces marginalization and oppression. Following the presentation of the poem "Circulation" written by Gabriell, we offer recommendations for meaningful and empowering ways to connect with marginalized youth. These recommendations emphasize acknowledging the diversity of experiences and developing authentic relationships.

\section{Standing Still}

This paper is a reflexive process inspired by the authors' experiences at the “Transforming Practices: Emancipatory Approaches to Youth Engagement workshop” - a threeday event in which researchers, practitioners, and youth met to discuss the complexities of youth engagement and empowerment. According to Macbeth (2001), reflexivity is described as a "deconstructive exercise for locating the intersections of author, other, text, and world, and for penetrating the representational exercise itself” (p. 35). The process of reflexivity involves the conscious and deliberate inclusion of the self (Dupuis, 1999) and often begins with a relatively

${ }^{1}$ This paper was a collaborative effort between Gabriell and Felice. Facebook and Google Docs were the locations in which we would meet to discuss ideas and engage in the co-creation of this paper. Notably, there are places in the text where we have inserted Gabriell's words verbatim to emphasize personal ideas and thoughts.

${ }^{2}$ Trans* with an asterisk is a popular stylization for transgender people. Trans* is symbolic of including and more than. It is used to escape the oppressive contexts of normal language.

3 Ze is a term used to reflect Gabriell's transgender identity; it is "a gender neutral pronoun that is an alternative to 'she' and 'he'” (Driskill, 2008, p. 6). 
International Journal of Child, Youth and Family Studies (2013) 3: 357-370

formal writing exercise such as a reflexive journal (Yuen, 2011). Writing can be used as a method of inquiry through discovery and analysis (Richardson, 2000) and has the potential to provide a context for critical reflexivity that evokes new questions (Richardson, 1999). In addition to journal writing, other methods used include letters (MacMahon, 1996) and poetry (Yuen, 2010).

Poetry initiated our engagement in reflexive practice and enabled the deconstruction of experiences beyond the workshop involving Gabriell's interactions with adults and social service providers. These experiences occurred in contexts that include youth shelters, emergency shelters, day centres, support groups, family support services, religious institutions, recreational facilities, and child and youth services. The deconstructive exercise was also inspired by interactions with teachers, guidance counsellors, community outreach workers, psychologists, and mental health professionals.

Locating the self is important in the reflexive process (Fine, 1994; Richardson, 1999). Thus, we include a brief introduction of the authors.

Felice: I am an associate professor at Concordia University and was a member of the organizing committee for the Transforming Practices workshop. My research focuses on examining leisure as a context for community development and capacity building. I grew up in Saskatoon, Saskatchewan with my parents, older sister, and dog named Dexter. As a youth, I experienced empowering opportunities through recreation and leisure activities such as summer camps, extracurricular sports, and art classes. One of my most compelling experiences was through an organization called Children's International Summer Villages (CISV). My experiences with this organization led me to pursue an academic career in leisure studies. My involvement in CISV had a strong influence on my perspective of leisure as a context for social capital development and community building with youth (see Yuen, Pedlar, \& Mannell, 2005). Like other researchers, I view leisure as a positive experience that contributes to the growth and development of young participants (see Caldwell \& Smith, 2006; Danish, Taylor, \& Fazio, 2003; Mahoney, Larson, \& Eccles, 2005; Witt \& Crompton, 1996; Witt \& Caldwell, 2010). The dialogue I was privileged to have with Gabriell led me to question the outcomes of the wellmeaning intentions of youth services providers (in leisure as well as other contexts) who inadvertently end up further marginalizing the youth they are trying to include, engage, and help.

Gabriell: I am a mental health advocate and activist. As I shared before, I am a trans* youth who feels marginalized from self-empowerment. I grew up in Wheaton, Maryland, close to the politics of Washington, DC. Members of my family were highly involved in public school administration, teaching, and education rights. Being so closely connected to a highly politicized environment led me to be highly sensitive and aware, yet feel alienated and disconnected from a social system that was designed to help and support. Interactions with the majority of adult role models I met in my childhood and adolescence were marginalizing. I recently have been evolving my feelings of oppression, by coming out as a trans* youth and subsequently advocating for more sensitive and mentally healthy governance and leadership. I have lived in emergency and homeless shelters. While these places covered my basic need for shelter, there was little emotional or psychological support. I repeatedly experienced a lack of information, insight, and safe spaces for listening, care, and intervention. From a very early age, I repeatedly 
ran away from emotional abuse, verbal abuse, sexual abuse, and physical abuse. I have also run from social systems that were supposed to help but ultimately created a sense of loss and alienation. I feel like my true self is underappreciated and misidentified. I self-identify as alien because I feel disconnected from service organizations and people who try to help, but lead me (and my friends) to feel like unknown and invisible people beyond help.

We are young and growing old without self-identity. Who we truly are has never been affirmed by the social systems holding our hands. It is like they try to tell us who we are and forget to let us ask ourselves who we really are. Oppressive rules, structures, and environments have denied my right to ask questions and seek information. Consequently, I was alienated from having knowledge of, and understanding the rationale behind the policies that ultimately dictated where and how I lived. These experiences, talking with Felice, and participating in other conferences have led me to believe the consequences of disconnected and alienated youth are due, in part, to misunderstanding and broken communication between adults and youth. It is our hope that this article will help build a bridge of understanding between adults and youth by embracing the humanity that encircles us all.

\section{Building the Bridge}

\section{Circulation}

Many people are running in circles

Many systems are running in circles

Many people we know are walking in circles

A circulation around what is important

So I stood still

Stillness

I stood still outside our circle

I stood still in our middle

People just circled

What do people do if people stand still?

I met few others who recognized and understood still, standing with me

I met many others who told me to keep walking

In circles

No place of understanding to stop and go

It shows

We know we are walking in circles

We do not know how to stop

Consciously and subconsciously, we know we are all in a circle

But we circle around each other without stopping to help 
International Journal of Child, Youth and Family Studies (2013) 3: 357-370

Our circulation around what is important

We leave humanity out of our circle

This poem was inspired by a get-to-know-you activity, which occurred at the beginning of the workshop. The activity was a movement exercise in which the facilitator had us randomly walk around a small space and greet people as we wished. The greetings were diverse. Felice did as she was told; she walked around, smiled, and shook people's hands as societal conventions dictate. Gabriell stood in one spot, briefly looking up and occasionally providing eye contact to individuals as they passed by.

\section{Many People are Running in Circles. Many Systems are Running in Circles. ...Stillness}

Empowerment is often a goal of youth service providers. According to Pedlar, Haworth, Hutchison, Taylor, and Dunn (1999), initial conceptualizations suggested that empowerment occurred when a relationship of dominance was established and individuals gained control over certain resources. However, as Pedlar and her colleagues' social ecological theory of empowerment suggests "one person becoming empowered does not require that others become proportionally disempowered; in fact people's life experiences appear most empowering when there is an equitable distribution of power” (p. 101). Striving for this kind of empowerment requires us to stop and reflect upon our practices and policies by engaging in stillness and questioning whether current processes encourage equitable distribution of power for youth. As stated by Westley, Zimmerman, and Patton (2006), "we live, by and large, in a culture that divorces contemplation or reflection from action” (p. 61). Consequently, practitioners, academics, policy-makers, and youth alike need to consciously pause and reflect upon their regular routines. "This is the way we've always done it" should not be the rationale for standard practice. Rather, decisions should be based on conscious, deliberate, and purposeful action.

This time for reflection is much like the process of standing still described by Westley and her colleagues (2006). They explain that standing still is a period for exploration that requires careful observation of details and their relationships to each other. Standing still is not necessarily a pleasant experience. Indeed, the authors state, "sometimes challenging the accepted wisdom may seem like spitting into the wind, a dampening experience” (p. 61). While this period of reflection is time consuming and may be unpleasant, it contributes to the development of meaningful relationships and change.

Inserting stillness into practice will enable service organizations and community leaders to effectively consider meaningful ways to empower the individuals with whom they are working. Individuals are complex systems; each person is unique and constantly changing (Westley et al., 2006) and each person's preferences, strengths, weaknesses, and motivations are different. As further suggested by Westley and her colleagues, working with complex systems requires balancing expertise with responsiveness. In other words, rigidity is counterproductive and organizational policies and procedures should offer enough flexibility for service providers to adequately respond to the specific context of each individual they encounter. For example, one 
of the homeless shelters Gabriell used told hir ${ }^{4}$ that ze had 30 days to stay there. Towards the end of the 30-day period, ze was beginning to feel physically and mentally well and was in the process of developing a direction for hir future. Because of hir progress, ze asked for more time and was rejected. Reflecting on hir experience, Gabriell writes, "It felt ugly, begging for time and having to explain why I felt better. There was a lot of pressure for both me and the staff both of us feeling pressured by their own rules.”

As Henderson (1996) contends, “one size doesn’t fit all” (p. 139). In her article, Henderson problematizes generalizations made when adopting a universal approach to policy development. While the context of the paper is leisure policy and women, her recommendations are useful for policy-makers and researchers as they engage in stillness. According to LadsonBillings (2000), “the ahistorical and acontextual nature of much law and other 'science' render the voices of the dispossessed and the marginalized group members mute” (p. 265). Henderson argues the consideration for personal dimensions such as class, race, gender, sexual orientation, and (dis)ability will contribute to the illumination of diversity, and historically and culturally specific experiences. Research and analyses that emphasize diversity underscore that some individuals are more disadvantaged because of multiple layers of oppression (Henderson, 1996). Social science and social policies have long been influenced from a patriarchal perspective (Dustin, 1992). This hegemonic authority has led to rigid structures that disempower and alienate the very individuals they were intended to help. Considerations for diversity will invariably highlight the multiple histories and experiences of youth and facilitate meaningful experiences of understanding and empowerment.

\section{Recognize and Understand ... Stand with Me}

"Policies and programs are often implicated with subtle and insidious forms of oppression, subjection, racism, discrimination, [and] undervaluation” (Fox \& Lashua, 2010, p. 234). Social systems and structures will become more contextualized and pluralistic if we take a moment to ask where the knowledge that informs social policies comes from, and ensure that diversity is a central aspect of the research that informs our practices. Adopting the perspective of a standpoint feminist will help facilitate considerations for diversity. Feminist standpoint theorists believe that "the dominant conceptual schemes of the...social sciences fit the experience that Western men of the elite classes and races have of themselves and the world around them.... By starting research from women's lives, we can arrive at empirically and theoretically more adequate descriptions and explanations” (Harding, 2004, p. 48). Such a perspective also involves the deconstruction of traditional understanding and experience by considering other positions of marginalization and oppression such as race and class (Olesen, 2000). Standpoint feminists argue that past research is only a partial understanding of the world and that a feminist perspective can provide another. Individuals who are marginalized and oppressed generally require time to heal. As Gabriell reflects on hir moments of healing, ze recalls, "I can't believe how many time I am asked why I need to heal.” While this kind of questioning may have come with good intentions, the mere question reflects a lack of acknowledgement (or knowledge) of hir personal story. Adopting a standpoint perspective would encourage us to ask not why but how we can help Gabriell heal.

\footnotetext{
${ }^{4}$ Hir is “a gender-neutral pronoun that is an alternative to `her' or 'his”” (Driskill, 2008, p. 3).
} 
International Journal of Child, Youth and Family Studies (2013) 3: 357-370

\section{No Place of Understanding to Stop and Go}

Providing opportunities and encouraging youth to engage in them will contribute to their empowerment as they take the time to reflect and develop their own identities and establish their own voices. An environment conducive to such experiences requires a sense of security and safety. Notably, Fox and Lashua (2010) emphasize that without consideration for the life experiences of youth, creating such environments may be harmful and may lead them to feel invisible. As these authors further contend, even though creating connections between marginalized youth and service providers is necessary, inclusion in mainstream programs and practices may not be an appropriate strategy. Mainstream programs tend to limit what we consider effective tools for empowerment, engagement, and citizenship. As stated by Fox and Lashua, mainstream systems and structures instead tend to reinforce efficiency and achievement, or "Euro-North-American values related to capitalism, excellence, people as expendable resources, and profit-lines.... [They] ignore the well-being and flourishing of human and nonhuman communities” (p. 238). As there is no blueprint for what is effective (Westley et al., 2006), we offer no list of methods to facilitate youth empowerment. Rather, we encourage youth service providers to develop authentic relationships with the youth they are working with. Effective and meaningful tools for youth empowerment will emerge from these relationships, where diversity, humanity, and an equitable distribution of power are emphasized.

\section{Bringing Humanity into our Circle}

Borrowing from Freire (2006a), we argue that true empowerment involves the humanization of all parties involved (e.g., adult and youth, oppressor and oppressed). All human beings ought to be engaged in meaningful relationships and dialogue so they can achieve critical awareness of their perspectives and discover their own and each other's potential for transformation. Discovering the potential for transformation involves focusing on the assets and strengths each person has. This process of discovery needs to reoccur because, as previously stated, people and their circumstances are constantly changing. Once perspectives are broadened and strengths are seen and used, humanity inevitably prevails and the type of empowerment where there is an equitable distribution of power becomes possible. As Pedlar and her colleagues (1999) state, "in situations where people [flourish], we noticed they treat each other differently.... Dreams and plans were taken seriously” (p. 102). They further contend:

The process and outcome of empowerment are mutually reinforcing among the people who interact with one another in that social context. This means that empowerment is much more dependent upon a balance of power among the interacting individuals than is suggested by conceptualizations which portray empowerment as resting on domination. (p. 102, original emphasis)

Social commitment, knowledge, aspirations, and openness are four conditions of the ecological theory of empowerment (Pedlar et al., 1999). These conditions are discussed in the following paragraphs. 
International Journal of Child, Youth and Family Studies (2013) 3: 357-370

Social commitment. In accordance with Pedlar and her colleagues, "the nature of the relationship people have with those who provide support to them is central to their well-being" (p. 109). They suggest an empowering relationship is based upon social commitment, which includes unconditional acceptance, endures challenge, and is sustainable. In their analysis of human service providers, the authors also emphasized that liking a person is an important aspect that is not often considered. The researchers found that in most empowering relationships, "there appeared to be an unspoken understanding - either that the support worker and the person being supported liked one another, as though it were a given; or alternatively, that it was irrelevant” (p. 110). Truly liking a person is important because it contributes forming a relationship centred upon humanity. As Gabriell states, "we are not working with a building, we are not working with a job title, we are working with a person.” An alien identity suffers from systematically encouraged emotionless neutrality. It is not enough to receive the empathetic response, "I understand." True encouragement, support, and acceptance are communicated and felt by expressions of a desire to understand. The following poem by Gabriell reflects what ze often hears (in regular font) and what would be more meaningful in hir experiences with youth service providers (in italics):

I understand you.

I want to understand you.

I will talk to you 'til I understand better.

I want to talk to you 'til I understand more

and I will not stop trying to understand

Conscious thought leading toward whether we like the people we are working with will contribute toward a more humanizing experience. It is better to change the people we are working with if personalities clash. Conscious thought toward our actions and expressing a desire to understand will contribute to building a bridge of understanding. These simple changes can contribute to authentic relationships and lead to empowering experiences.

Knowledge. The ability to act upon one's knowledge is as important as the knowledge itself. Pedlar and her colleagues (1999) suggest that, "knowledge of how human service systems and policies are devised and operationalized is a significant factor in the kind of support a person ultimately receives. Policies are often complex and difficult to navigate” (p. 104). For many youth, there is little opportunity to participate in the production of knowledge. Furthermore, as previously stated, youth are generally not privy to the knowledge affecting the operational decisions of the systems that involve them.

Even when Gabriell participated in programs designed to promote youth-leadership, the unspoken guidelines were "rules first, ask second". That is, youth participants were expected to simply follow the rules set up by the organization. There was no opportunity to reflect and analyze these rules (i.e., to understand and question the rationale behind the rules) or to participate in the actual development of these rules. These experiences of forced ignorance contributed to hir exclusion from participating and engaging in civic society. Being informed, creating knowledge, and participating in the development of policies that affect one's life can be freeing from self-identifying as alien. Creating an environment that is centred on humanity should include both opportunities for open discussions about policies as well as potential for 
change. Transparency is a critical aspect of these discussions. Those who gain access to knowledge are then able to use it. As described by Pedlar and her colleagues, empowerment through the acquisition of knowledge and understanding is a cumulative process as though “people’s sense of potency and energy grows stronger with each success” (p. 107).

Aspirations. To aspire is "the ability and willingness to visualize a bright future, along with a desire to grow and to experience those possibilities (Pedlar, et al., 1999, p. 107). To aspire and to hope are a part of what makes us human; they are a part of the humanity that encircles us all. Empowering experiences are fuelled by youth's opportunities for hope. As Freire (2006b) contends, hope is attained through action. Moreover, aspirations need to be supported and encouraged by others (Pedlar et al., 1999). Through the development of meaningful relationships with youth services providers, youth's ideas and dreams can be shared without shame and without fear of judgment. But it is so hard to do that Gabriell has been heard too many times. Such a response to hir ideas and dreams evokes feelings of being forced to stay on the margins, ultimately reinforcing the identification with being alien. Marginalized youth are too well aware of barriers that constrain their hopes and dreams for the future. Rather than emphasizing the barriers, encouraging discussion with youth will enable them to further their reflections and decide for themselves whether their aspirations are realistic and feasible. These conversations should involve the disclosure of organizational policies, procedures, and societal norms that may be inhibiting the potential for their dreams to become reality. Notably, the purpose of this disclosure is not to provide a rationale but to collectively engage in critical inquiry into both the aspirations of the youth and what has been accepted as conventional wisdom.

Sometimes it is the mere act of dreaming and having someone believe in the dreamer's potential to achieve it that matters most, as opposed to the actual dream itself. In accordance with Pedlar et al. (1999), "in contrast to those who simply stopped at empathy, staff who shared people's belief in their ability and who were committed to helping them improve their quality of life greatly facilitated their attempt to realize their dreams (p. 108).”

Part of being human is a constant iteration of dreaming, believing, and achieving or failing. Having someone believe in our potential to dream and achieve is an important process. As Gabriell reflects, "we need to dream to change and we need systems to dream with us." While the specific aspiration that has been articulated may not be achieved, the fact that someone believes and trusts in one's ability to dream will foster the desire to continue dreaming and contribute to a sense of empowerment to move towards a greater quality of life.

Openness. Openness is considered the most important condition of empowerment because the other three components (social commitment, knowledge, and aspiration) contributed more to empowerment when they were characterized by a sense of openness. Pedlar and her colleagues (1999) argue:

The knowledge that really counts is knowledge concerning...opportunities [to participate in one's life]. The aspirations that really count are aspirations to take on the challenges such opportunities present. The social commitment that really counts envisages the person to whom one is committed. (p. 112) 
International Journal of Child, Youth and Family Studies (2013) 3: 357-370

Unfortunately, it is rare for marginalized youth to have experiences of true openness. While they are told disclosure is healthy, the disclosure that actually occurs is one-sided.

In Gabriell's experience, there is a normative expectation that youth should tell all to adults. As ze states, "It would be nice to walk into an organization that lets you understand their own history; where their policies come from, and how they came into existence.” If the process and outcome of empowerment is to be mutually reinforcing, openness should be an expectation of every party involved in the relationship. In the previous section we mentioned the idea of collective engagement in stillness. This process, which is characterized by mutual openness and transparency, involves critical and analytical discussions between youth and adults about aspirations and procedural norms. Understanding increases, perspectives are broadened, and opportunities for meaningful outcomes for both the youth and agency can be found by entering into stillness together.

\section{Conclusion: Standing Still ... Again}

Humanity has been repeatedly emphasized throughout this paper and is arguably the foundation required to build empowering relationships between adults and youth. Acknowledging the diverse experiences and histories of the youth we encounter will contribute to including humanity in the policies and procedures we create. Forming authentic relationships which are characterized by commitment, the co-creation of knowledge, the sharing of and believing in hopes and dreams, and openness will enable us to embrace the humanity that unites us all. Empowering outcomes require both adults and youth to engage in stillness - individually and collectively. Entering into stillness will facilitate the acknowledgement of diversity and the formation of authentic relationships. Returning to the title of Gabriell's poem, Circulation, we are still circulating, but with humanity at the core and with the opportunity to stand still.

Undoubtedly, some of these recommendations do not resonate with dominant values of productivity, efficiency, and, some may even argue, professionalism. Engaging in a reflexive practice involves a deconstructive process that has the potential to evoke more questions (McMahon, 1996). There are implications of these recommendations that raise some critical questions. Is the luxury of taking the time to reflect possible in a profession that is already understaffed? Of what use is engaging in philosophical dialogue when the primary concern is moving our clients towards independence? How will we secure funding by adopting these practices? It is not our intention to undermine these questions by not addressing them. We intend to continue reflecting on the implications and we urge readers to do the same.

Some readers may perceive our recommendations as great change and maybe even impossible, while others will see them as small change. As Gabriell contends, "connecting with aliens is serious business. Structural changes are needed to break through the very walls meant to create order." Placing humanity, diversity, and relationship at the core of organizational policies is possible and has been done in other areas of human service, for example in some organizations which work with adults who have developmental disabilities (Pedlar et al., 1999) and in some organizations which work with women who have been in conflict with the law (Yuen, Thompson, \& Pedlar, 2005; Yuen, 2008). According to Henderson (1996), "individual empowerment is key, [but] only collective action can effectively generate lasting social 
International Journal of Child, Youth and Family Studies (2013) 3: 357-370

transformation” (p. 151). It is our hope that we have inspired readers to reconsider the standard practices and policies that guide our interactions and decisions from the perspective of marginalized youth. We also hope that readers will find their own ways to embrace the humanity that encircles us all. 
International Journal of Child, Youth and Family Studies (2013) 3: 357-370

\section{References}

Caldwell, L. L., \& Smith, E. A. (2006). Leisure as a context for youth development and delinquency protection. Australian and New Zealand Journal of Criminology, 39(3), 398-498.

Context(e, G. (2012, June 5). Circulation [Facebook Wall Post]. Retrieved from https://www.facebook.com/prosody/posts/795595029504?comment_id=1932152

Danish, S. T., Taylor T. E., \& Fazio, R. J. (2003). Enhancing adolescent development through sports and leisure. In G. R. Adams \& M. D. Berzonsky (Eds.), Blackwell handbook of adolescence. Blackwell handbooks of developmental psychology (pp. 92-108). Malden, ME: Blackwell Publishing.

Driskill, Q-L. (2008). Gender glossary. East Lansing, MI: Dragonfly Arising Press Organizers Pamphlet \#2. Retrieved April 18, 2013 from http://dragonflyrising.wearetheones.info/GenderGlossaryDragonfly.pdf

Dupuis, S. L. (1999). Naked truths: Towards a reflexive methodology in leisure research. Leisure Sciences, 21, 43-64.

Dustin, D. L. (1992). The dance of the dispossessed: On patriarchy, feminism, and the practice of leisure sciences. Journal of Leisure Research, 16, 46-60.

Fine, M. (1994). Working the hyphens: Reinventing self and other in qualitative research. In N. K. Denzin \& Y. S. Lincoln (Eds.), Handbook of qualitative research (pp. 70-82). Thousand Oaks, CA: Sage Publications, Inc.

Fox, K. M., \& Lashua, B. D. (2010). Hold gently people who create space on the margins: Urban Aboriginal-Canadian young people and hip hop rhythms of "leisures.” In H. Mair, S. M. Arai, \& D. G. Reid (Eds.), Decentring work: Critical perspectives on leisure, social policy, and human development (pp. 229-250). Calgary, AB: University of Calgary Press.

Freire, P. (2006a). Pedagogy of hope. New York: Continuum.

Freire, P. (2006b). Pedagogy of the oppressed. New York: Continuum.

Harding, S. (2004). How standpoint methodology informs philosophy of social science. In S. N. Hesse-Biber \& P. Leavy (Eds.), Approaches to qualitative research (pp. 62-80). New York: Oxford University Press.

Henderson, K. (1996). One size doesn’t fit all: The meanings of women's leisure. Journal of Leisure Research, 20(3), 139-154. 
International Journal of Child, Youth and Family Studies (2013) 3: 357-370

Ladson-Billings, G. (2000). Racialized discourses and ethnic epistemologies. In N. K. Denzin \& Y. S. Lincoln (Eds.), Handbook of qualitative research (2nd ed., pp. 257-277). Thousand Oaks: Sage Publications, Inc.

Macbeth, D. (2001). On “Reflexivity” in qualitative research: Two readings, and a third. Qualitative Inquiry, 7(1), 35-68.

Mahoney, J. L., Larson, R. W., \& Eccles, J. S. (2005). Organized activities as contexts of development: Extracurricular activities, after school and community programs. Mahwah, NJ: Lawrence Erlbaum Associates, Inc.

McMahon, M. (1996). Significant absences. Qualitative Inquiry, 2(3), 320-336.

Olesen, V. L. (2000). Feminism and qualitative research at and into the millennium. In N. K. Denzin \& Y. S. Lincoln (Eds.), Handbook of qualitative research (2nd ed., pp. 215-256). Thousand Oaks, CA: Sage Publications.

Pedlar, A., Haworth, L., Hutchison, P., Taylor, A., \& Dunn, P. (1999). A textured life. Empowerment and adults with developmental disabilities. Waterloo, ON: Wilfred Laurier Press.

Richardson, L. (1999). Feathers in our CAP. Journal of Contemporary Ethnography, 28(6), 660668.

Richardson, L. (2000). Writing, a method of inquiry. In N. K. Denzin \& Y. S. Lincoln (Eds.), Handbook of qualitative research (2nd ed., pp. 923-948). Thousand Oaks, CA: Sage Publications.

Westley, F., Zimmerman, B., \& Patton, M. Q. (2006). Getting to maybe, how the world is changed. Toronto: Vintage Canada.

Witt, P. A., \& Caldwell, L. L. (2010). The rationale for recreation services for youth: An evidence-based approach. Retrieved from National Recreation and Park Association website: http://www.nrpa.org/uploadedFiles/nrpa.org/Publications_and_Research/Research/Papers Witt-Caldwell-Summary.pdf

Witt, P. A., \& Crompton, J. L. (1996). The at-risk youth recreation project. Journal of Park and Recreation Administration, 15(3), 1-9.

Yuen, F. (2008). Walking the red road: Aboriginal federally sentenced women's experiences in healing, empowerment, and re-creation. Unpublished doctoral dissertation, University of Waterloo, Waterloo, ON.

Yuen, F. (2010). Kicking and screaming. International Review of Qualitative Research, 2(4), 429-432. 
International Journal of Child, Youth and Family Studies (2013) 3: 357-370

Yuen, F. (2011). Embracing emotionality: Clothing my “naked truths”. Critical Criminology, 19(1), 75-88.

Yuen, F., Pedlar, A., \& Mannell, R. C. (2005). Building community and social capital through children's leisure in the context of an international camp. Journal of Leisure Research: Special Issue, Leisure and Social Capital, 37(4), 494-518.

Yuen, F., Thompson, J., \& Pedlar, A. (2006). Engagement in leisure: A restorative justice approach to working with incarcerated women. Restorative Directions Journal, 2(1), 22-35. 